\title{
The role of antibody expression and their association with bladder cancer recurrence: a single-centre prospective clinical-pilot study in 35 patients
}

Peter Ella-Tongwiis ${ }^{1,2}$, Rebecca May Lamb ${ }^{4}$, Alexander Makanga ${ }^{3}$, Iqbal Shergill ${ }^{1,2,5}$ and Stephen Fôn Hughes ${ }^{1,2^{*}}$ (D)

\begin{abstract}
Background: Bladder cancer (BC) is the 10th most common cancer in the UK, with about 10,000 new cases annually. About $75-85 \%$ of $B C$ are non-muscle invasive (NMIBC), which is associated with high recurrence and progression rates (50-60\% within 7-10 years). There are no routine biomarkers currently available for identifying BC patients at increased risk of developing recurrence. The focus of this research study was to evaluate antibody expression in BC patients and their association with cancer recurrence.

Methods: 35 patients scheduled for TURBT were recruited after written informed consent. Ethical approval for the project was granted via IRAS (REC4: 14/WA/0033). Following surgical procedure, tissues were preserved in 10\% buffered formalin and processed within $24 \mathrm{~h}$ in FFPE blocks. 7 sections ( $4 \mu \mathrm{m}$ each) were cut from each block and stained for CD31, Human epidermal growth factor receptor-2 (HER-2), S100P, Cyclooxygenase-2 (COX-2), VEGFR-3 thrombomodulin and CEACAM-1 using immunohistochemistry. Clinical outcome measures (obtained via cystoscopy) were monitored for up to 6 months following surgical procedure.
\end{abstract}

Results: There was significantly increased expression of CD31 ( $p<0.001)$, HER-2 $(p=0.032), \operatorname{S100P}(p<0.001), \operatorname{COX}-2$ $(p<0.001)$, VEGFR-3 $(p<0.001)$ and decreased expression of thrombomodulin $(p=0.010)$ and CEACAM-1 $(p<0.001)$ in bladder tumours compared to normal bladder tissues. HER-2 expression was also significantly associated with cancer grade $(p=0.003)$, especially between grade 1 and grade $2(p=0.002)$ and between grade 1 and grade $3(p=0.004)$. There was also a significant association between cancer stage and HER-2 expression ( $p<0.001)$. Although recurrence was significantly associated with cancer grade, there was no association with antibody expression.

Conclusion: Findings from the present study may indicate an alternative approach in the monitoring and management of patients with BC. It is proposed that by allowing urological surgeons access to laboratory markers such as HER-2, Thrombomodulin and CD31 (biomarker profile), potentially, in the future, these biomarkers may be used in addition to, or in combination with, currently used scoring systems to predict cancer recurrence. However, verification and validation of these biomarkers are needed using larger cohorts.

Keywords: Immunohistochemistry, Recurrence, Biomarkers, Bladder

\footnotetext{
*Correspondence: Stephen.hughes6@wales.nhs.uk

1 North Wales Clinical Research Centre, Betsi Cadwaladr University Health

Board (BCUHB), Wrexham Maelor Hospital, Wrexham, Wales, UK

Full list of author information is available at the end of the article
}

(c) The Author(s) 2020. This article is licensed under a Creative Commons Attribution 4.0 International License, which permits use, sharing, adaptation, distribution and reproduction in any medium or format, as long as you give appropriate credit to the original author(s) and the source, provide a link to the Creative Commons licence, and indicate if changes were made. The images or other third party material in this article are included in the article's Creative Commons licence, unless indicated otherwise in a credit line to the material. If material is not included in the article's Creative Commons licence and your intended use is not permitted by statutory regulation or exceeds the permitted use, you will need to obtain permission directly from the copyright holder. To view a copy of this licence, visit http://creativecommons.org/licenses/by/4.0/. The Creative Commons Public Domain Dedication waiver (http://creativecommons.org/publicdomain/zero/1.0/) applies to the data made available in this article, unless otherwise stated in a credit line to the data. 


\section{Background}

Globally, there were approximately 549,393 new bladder cancer (BC) diagnoses in 2018 of which about $90 \%$ are Transitional cell carcinomas (TCC) [1]. An estimated $80 \%$ of TCC are Non-Muscle Invasive (NMIBC) while about $20 \%$ are Muscle Invasive BC (MIBC). High recurrence rates in NMIBC means patients are exposed to frequent hospital visits with increased risks of infection and post-operative complications. The Transurethral Resection of the Bladder Tumour (TURBT) is still the main procedure for treatment and diagnosis of $\mathrm{BC}$. Insufficient resection has been associated with an increased risk of early recurrence [2].

Although there is intense ongoing BC-related research, no routinely used biomarkers exist for predicting recurrence following TURBT. Cyclooxygenase-2 (COX-2) plays important roles in the inflammatory response [3] with high expression of COX-2 being reported in high grade and high stage colorectal cancer [4] and endometrial carcinoma [5].

Thrombomodulin is a $74 \mathrm{kDa}$ membrane receptor expressed on endothelial cells with important roles in physiological coagulation, inflammation and cancer promotion [6,7]. The effects of Thrombomodulin activity in cancer have been linked to its roles in anticoagulation, anti-inflammation and tissue adhesion and proliferation [8].

The S100 proteins are associated with cellular processes such as regulation of cell cycle, growth, transcription and differentiation [9]. It is thought that, when secreted, S100P may have paracrine or autocrine signalling effects [10], while cellular expression of S100P may interact with growth factors and receptors leading to several effects such as proliferation [9]. The association between S100P and cellular processes such as cell survival, proliferation, tumour invasion and angiogenesis have been studied by various researchers $[9,11-13]$.

As an oncogene, HER2 over-amplification causes tumourigenesis due to activation of signalling pathways such as MAPK $[14,15]$. HER2 gene amplification and higher protein expression occurs in about $25 \%$ of people with metastatic breast cancer [16].

Even though VEGFR-3 expression is usually located on endothelial cells within the lymphatic system [17] and has been mainly involved in lymphangiogensis [18]. Some studies have observed that any inhibition of VEGFR-3 activity, reduces Angiogenic sprouting and vascular network formation [19]. Due to the high recurrence rates in $\mathrm{BC}$, measurement of VEGF and their receptors may provide useful for predicting recurrence and progression.

Decreased expression, down regulation or loss of CEACAM-1 expression in tumour cells has previously been reported [20, 21]. In hepatocellular carcinoma, loss of CEACAM-1 expression is significantly associated with high grade and poor survival [22].

CD31 plays various roles in angiogenesis, leucocyte migration and activation of integrins $[23,24]$ and may be secreted, membrane bound or localised intracellularly. Increased CD31 expression has also been associated with worst cancer specific survival [25] and poor prognosis [26].

Findings from the present study may indicate an alternative approach in the monitoring and management of patients with $\mathrm{BC}$. It is proposed that by allowing urological surgeons access to laboratory markers such as HER-2, Thrombomodulin and CD31 (biomarker profile), potentially, in the future, these biomarkers may be used in addition to, or in combination with, currently used scoring systems to predict cancer recurrence. However, verification and validation of these biomarkers are needed using larger cohorts.

\section{Methods}

Ethical approval and subject recruitment

Permission for this research study was granted by the Research Ethics Service (REC reference 14/WA/0033). Subjects recruited for this research attended the Betsi Cadwaladr University Health Board (BCUHB) Wrexham Maelor Hospital, North Wales for elective procedures for the treatment/management of $\mathrm{BC}$ (Table 1). 35 patients (average age $=74$, males $=29$ and females $=6$ ) prospective patients scheduled for a Transurethral Resection of the Bladder tumour (TURBT) for the treatment of $\mathrm{BC}$,

\begin{tabular}{|c|c|c|}
\hline Age (years) & & \\
\hline Mean & & 74 \\
\hline Median & & 75 \\
\hline Range & & 43-95 \\
\hline \multicolumn{3}{|l|}{ Sex } \\
\hline Male & & 29 \\
\hline Female & & 6 \\
\hline \multicolumn{3}{|l|}{ Cancer stage } \\
\hline pTa & & 22 \\
\hline pT1 & & 6 \\
\hline pT2 & & 5 \\
\hline \multicolumn{3}{|l|}{ Cancer grade } \\
\hline Grade 1 & & 9 \\
\hline Grade 2 & & 11 \\
\hline Grade 3 & & 13 \\
\hline \multicolumn{3}{|c|}{ Cancer recurrence } \\
\hline Recurrence & & 14 \\
\hline No recurrence & & 21 \\
\hline
\end{tabular}


were recruited into this research study after informed consent.

\section{Tissue preservation, processing and microtomy}

Formalin Fixed, Paraffin Embedded (FFPE) tissue blocks of recruited patients were retrieved from storage at the histopathology department of Ysbyty Glan Clwyd, North Wales (UK). At least 12 sections $(4 \mu \mathrm{m}$ each) were cut from each patient tissue block using a microtome, placed on positively charged glass microscope slides and incubated at $60^{\circ} \mathrm{C}$ for at least $30 \mathrm{~min}$ before proceeding with IHC. This process enhances adherence of the tissue to the glass slides and ensures stability of the tissue.

\section{Antibodies}

Monoclonal anti-CEACAM-1/CD66a (clone: 283324; R\&D systems UK), monoclonal anti-CD31 (clone: JC70; cell marque UK), Polyclonal anti-COX-2 (Clone: SP21; cell marque UK), monoclonal anti-HER-2/neu (Clone: 4B5; Roche diagnostics UK), monoclonal anti-S100P (clone: 16/f5; Cell marque UK), monoclonal anti-thrombomodulin (clone: 1009; Cell marque UK) and monoclonal anti-VEGFR-3 (clone: AF349; R\&D systems UK) were used in this study. Antibodies were stored and treated according to manufacturer's instructions.

\section{Immunohistochemistry}

Tissue slides were dewaxed using 1X EZ prep solution (Ventana Medical Systems, UK), heat and vortex mixing and antigen retrieval was carried out using cell condition 1. VENTANA Antibody Diluent with Casein was used to block endogenous proteins. This was followed by the application of primary antibodies which primarily were mouse and rabbit IgG. The antigens were then visualised using Ventana Ultraview DAB universal detection kit. The slides were then counter stained using Ventana haermatoxylin 1 . The slides were washed in warm soapy water to remove residual liquid coverslip (oil) and the then dehydrated in a series of alcohol and DPX mounted on Dako HE autostainer. For each IHC stain, both positive and negative control tissue were used to ensure validity of the results.

\section{Assessing recurrence}

In all patients recruited into this research study, follow up data immediately available from follow up clinics was retrieved. This information was obtained from outpatient clinic as well as BCUHB clinical portal.

Investigating the long-term overall survival rates, 5-year and 10-year recurrence and progression data are, however, beyond the scope of this research. However, the short-term information available (up to 2 years post TURBT) will be discussed in relation to the biomarkers measured and may ultimately provide sufficient and accurate clinical data that may help predict or forecast NMIBC recurrence and progression.

\section{Statistical analysis}

Statistical analysis was undertaken using SPSS (version 26). With regards to tissue analysis, a chi-square test was performed to determine the difference between antibody staining in bladder tumour cells in comparison with normal urothelium. A Kruskal Wallis test was used to determine the association between clinopathological features (such as cancer grade and stage) and expression. In cases where there was a significant difference, further post-hoc testing was performed using the Mann-Whitney test.

\section{Results}

\section{CD31 tissue expression in BC patients}

Anti-CD31 primary monoclonal antibody demonstrated cytoplasmic and membranous staining patterns in endothelial cells (Fig. 1). Vascular endothelial cells in $\mathrm{BC}$ tissues had significantly higher anti CD31 expression, compared to normal underlying tissues $\left(\mathrm{X}^{2}(3)=20.353\right.$, $p<0.001)$, as determined by the Chi-square test. With respect to cancer grading and staging, there was no significant association between patients' cancer grade and CD31 $\left(\mathrm{X}^{2}(2)=2.719, p=0.257\right)$, as determined by the Kruskal-Wallis test. However, there was a significant association with cancer stage $\left(\mathrm{X}^{2}(2)=12.276, p=0.002\right)$, as determined by the Kruskal-Wallis test.

\section{Thrombomodulin tissue expression in $\mathrm{BC}$ patients}

The anti-thrombomodulin primary monoclonal antibody used in this study shows membranous staining patterns in $\mathrm{BC}$ tissue sections (Fig. 2). Positive membranous staining was reported based on colour intensity and percentage of cells that were expressed. Generally, there was a significantly reduced thrombomodulin in Bladder tumours, compared to normal underlying tissues $\left(\mathrm{X}^{2}(3)=11.29\right.$, $p<0.010$ ), as determined by the Chi-square test.

With respect cancer grading and staging, there was no significant association between patients' cancer grade and Thrombomodulin $\left(\mathrm{X}^{2}(2)=0.380, p=0.83\right)$, as determined by the Kruskal-Wallis test. There was however a significant association between patient's cancer stage and Thrombomodulin $\left(\mathrm{X}^{2}(2)=6.50, p=0.039\right)$, as determined by the Kruskal-Wallis test.

\section{HER-2/neu tissue expression in BC patients}

The anti-HER-2/neu primary monoclonal antibody used in this study shows membranous staining patterns in BC tissue sections (Fig. 3). Positive membranous staining was reported based on colour intensity and percentage of cells staining positive. Generally, there was a significantly 

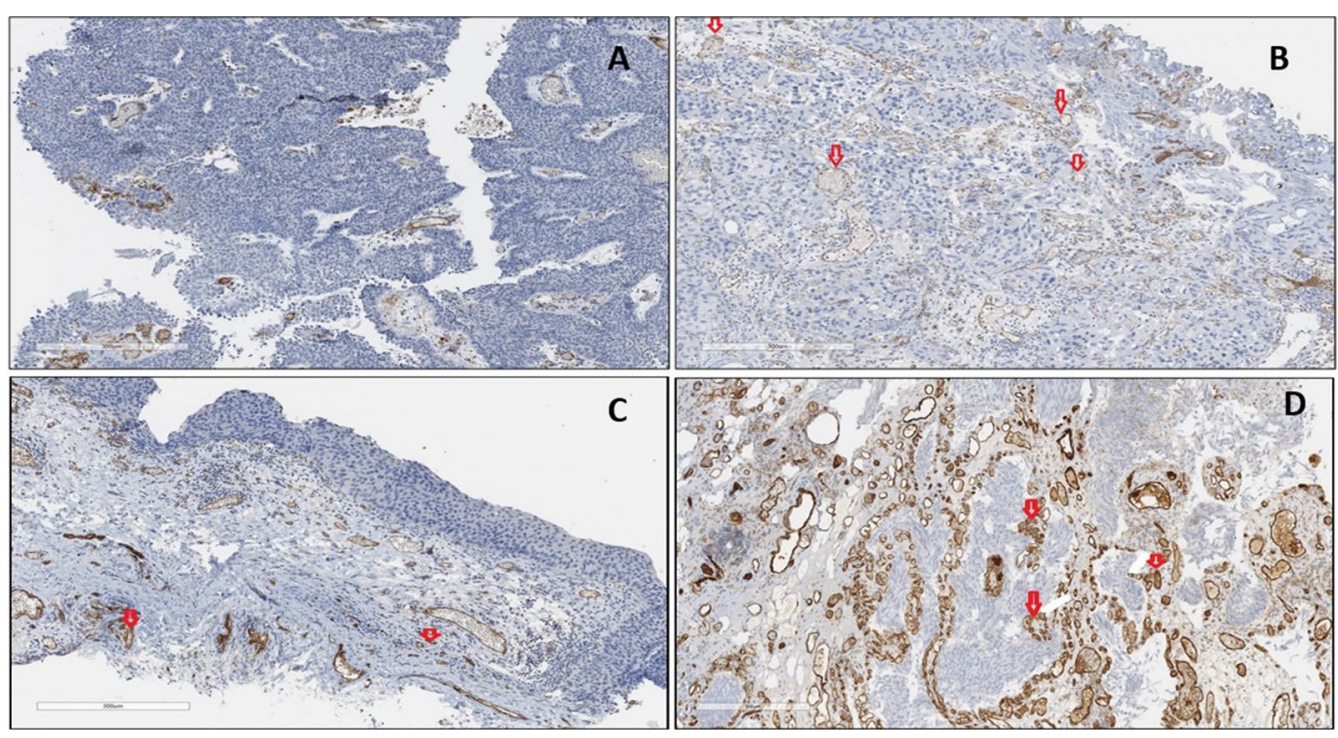

Fig. 1 Anti-CD31 antibody staining in BC tissues. a Negative: No staining or positive cytoplasmic/membranous staining in $<5 \%$ of $V E$ cells in $B C$ tissues. b Positive (+: Weak intensity cytoplasmic/membranous staining in up to 20\% of VE cells in BC tissues. c Positive (++): Moderate intensity cytoplasmic/membranous staining in 20-50\% of VE cells in BC tissues. d Positive (+++): Strong cytoplasmic/membranous staining in $>50 \%$ of VE cells in $B C$ tissues. DAB detection. $\times 40$ magnification. $V E$, vascular endothelial

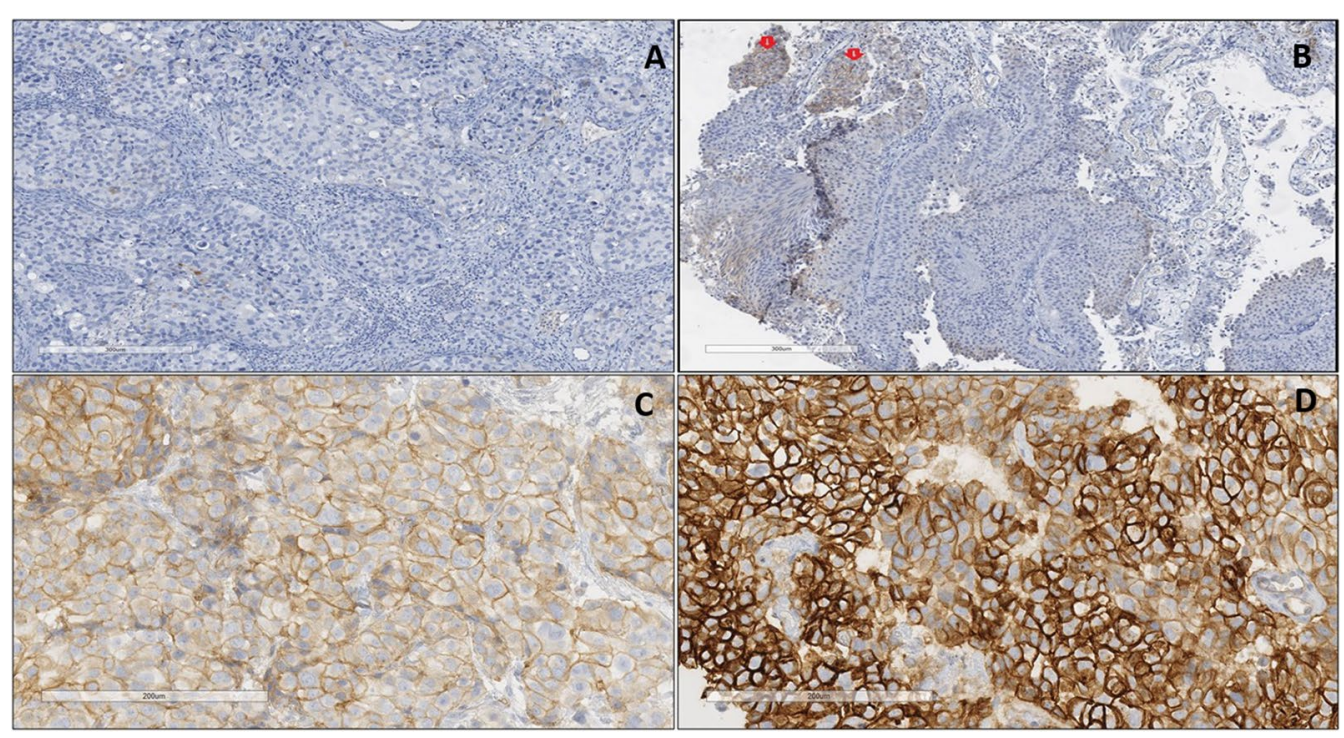

Fig. 2 Anti-thrombomodulin IHC staining in BC tissues. a Negative: No membranous staining in $<5 \%$ of Bladder tumours b Positive (+): Positive membranous staining in up to $20 \%$ of Bladder tumours. Note the weak positive membranous staining (red arrows). c Positive (++): Positive membranous staining in up to $20-50 \%$ of Bladder tumours. Note the Moderate colour intensity. $\mathbf{d}$ Positive (+++): Positive membranous staining in $>50 \%$ of Bladder tumours. Note the high colour intensity. DAB detection. $\times 40$ magnification

higher HER-2/neu expression in Bladder tumours, compared to normal underlying tissues $\left(\mathrm{X}^{2}(3)=8.82\right.$, $p<0.032)$, as determined by the Chi-square test.

With respect cancer grading, there was a significant association between patients' cancer grade and HER-2/ neu $\left(\mathrm{X}^{2}(2)=11.407, p=0.003\right)$, as determined by the Kruskal-Wallis test. Further post-hoc testing using the Mann-Whitney test revealed significant difference between grade 1 and grade $2(Z=-3.042, p=0.002$, $\mathrm{r}=0.673)$ and a significant difference between grade 1 

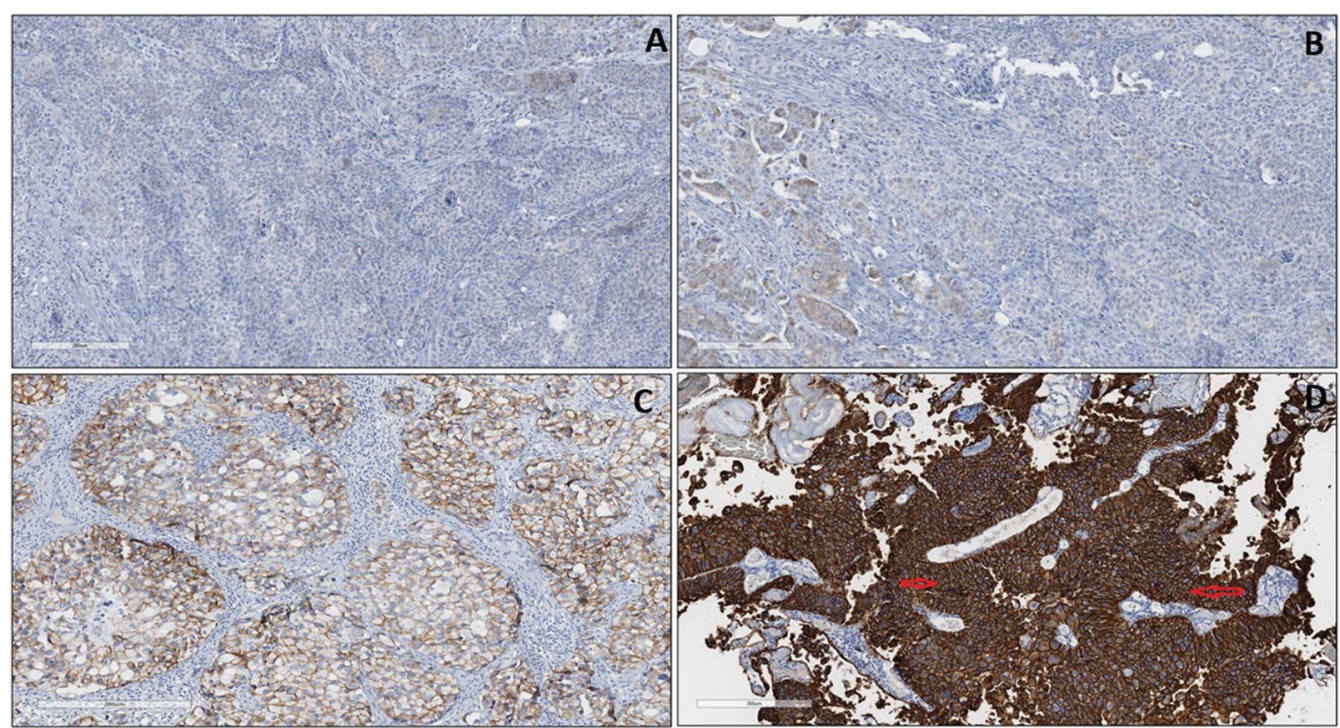

Fig. 3 Anti-HER-2/neu antibody staining in BC tissues. a Negative: No staining or weak membranous staining in $<5 \%$ of $B C$ tissues. $\mathbf{b}$ Positive (+): Weak intensity membranous staining in up to $20 \%$ BC tumours. c Positive (++): Moderate intensity membranous staining in 20-50\% of BC tissues. d Positive $(+++)$ : Strong intensity membranous staining in $>50 \%$ of BC tissues (Brown colour, red arrows). DAB detection. $\times 40$ magnification

and grade $3(\mathrm{Z}=-2.843, p=0.004, \mathrm{r}=0.606)$, both with a high $\mathrm{Eta}^{2}$ effect size. There was also a significant association between patient's cancer stage and HER-2/neu $\left(\mathrm{X}^{2}(2)=16.092, p<0.001\right)$, as determined by the KruskalWallis test.

\section{S100P tissue expression in BC patients}

The anti-S100p primary monoclonal antibody used in this study shows cytoplasmic and nuclear staining patterns in BC tissue sections (Fig. 4). Generally, there was a significant increase in S100P expression in Bladder tumours
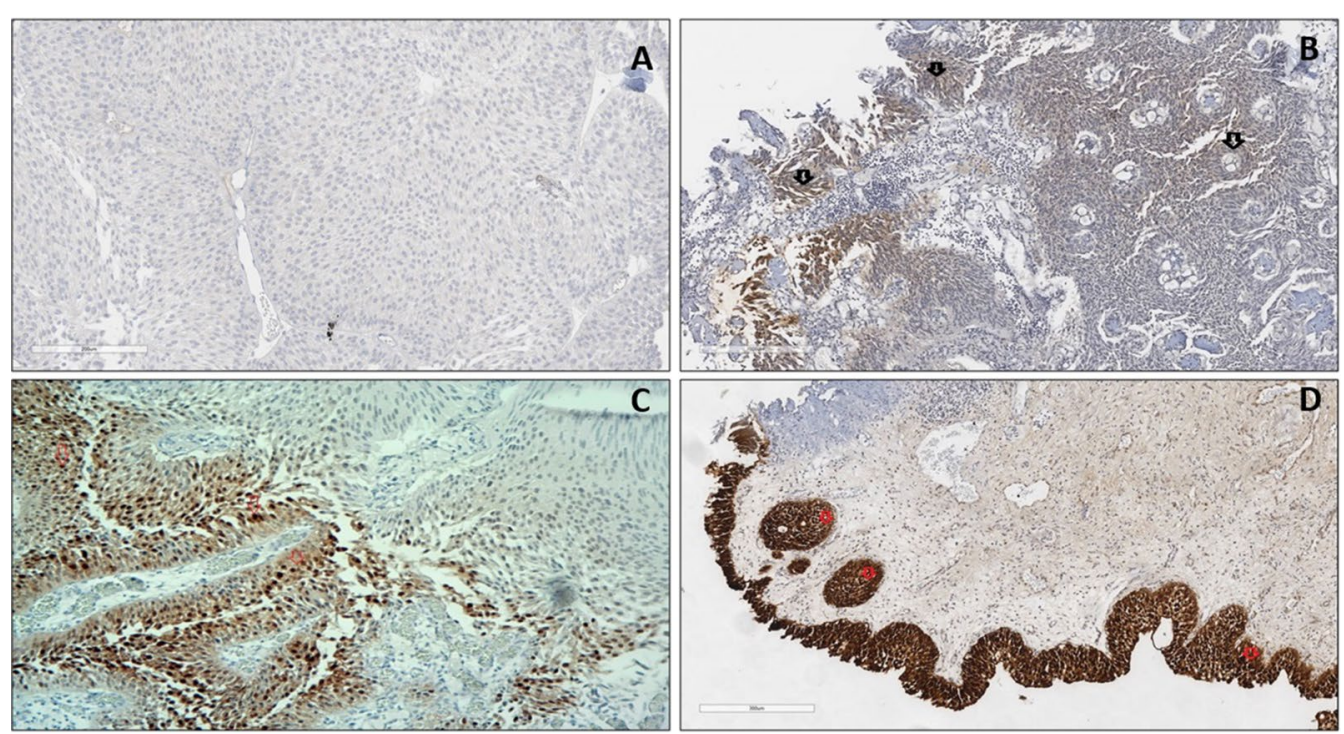

Fig. 4 Anti-S100P antibody staining in BC tissues. a Negative: No staining or positive cytoplasmic/nuclear staining in $<5 \%$ of Bladder tumours. $\mathbf{b}$ Positive (+): Weak Nuclear/cytoplasmic staining in up to 20\% of Bladder tumours (black arrows). c Positive (++): Moderate/strong positive nuclear and cytoplasmic staining $20-50 \%$ of Bladder tumours. $\mathbf{d}$ Positive $(+++)$ : Strong positive nuclear and cytoplasmic staining in $>50 \%$ of Bladder tumours. DAB detection. X40 magnification 
compared to those in normal tissues $(\mathrm{X} 2(3)=41.686$, $p<0.001)$, as determined by the Chi-square test.

With respect to cancer grading, there was no significant association between patients' cancer grade and anti-S100P expression $\left(\mathrm{X}^{2}(2)=0.206, p=0.902\right)$, as determined by the Kruskal-Wallis. There was also no significant association between patient's cancer stage and S100P $\left(\mathrm{X}^{2}(2)=2.134, p=0.344\right)$, as determined by the Kruskal-Wallis test.

\section{COX-2 tissue expression in $\mathrm{BC}$ patients}

The anti-COX-2 primary monoclonal antibody used in this study shows cytoplasmic and membranous staining patterns in BC tissue sections (Fig. 5). Generally, there was a significant increase in COX-2 expression in Bladder tumours, compared to those in normal tissues $(\mathrm{X} 2(3)=19.97, p<0.001)$, as determined by the Chisquare test. With respect to cancer grading, there was no significant association between patients' cancer grade and anti-COX-2 $\left(\mathrm{X}^{2}(2)=0.96, p=0.61\right)$, as determined by the Kruskal-Wallis test. There was also no significant association between patient's cancer stage and S100P $\left(\mathrm{X}^{2}(2)=1.65, p=0.45\right)$, as determined by the KruskalWallis test.

\section{Anti-CEACAM-1 tissue expression in BC patients}

The anti-CEACAM-1 primary monoclonal antibody used in this study shows cytoplasmic/membranous staining patterns in BC tissue sections (Fig. 6). Generally, there was a significant change (loss of tissue expression) in CEACAM-1 in Bladder tumour, compared to normal tissues $(\mathrm{X} 2(3)=11.29, p<0.001)$, as determined by the Chisquare test.

There was a significant association between patients' cancer grade and CEACAM- 1 expression $\left(\mathrm{X}^{2}(2)=6.19\right.$, $p=0.045$ ), as determined by the Kruskal-Wallis. Further post-hoc testing using the Mann-Whitney test revealed significant difference between grade 1 and grade $3(\mathrm{Z}=-2.444, p=0.015, \mathrm{r}=0.509)$. With respect to cancer staging, there was a significant association between patient's cancer stage and CEACAM-1 expression $\left(\mathrm{X}^{2}(2)=10.78, p=0.005\right)$, as determined by the KruskalWallis test.

\section{Anti-VEGFR-3 tissue expression in BC patients}

The anti-VEGFR-3 primary monoclonal antibody used in this study shows nuclear and cytoplasmic staining patterns in BC tissue sections (Fig. 7). Generally, there was a significant increase in VEGFR-3 expression in Bladder tumours, compared to normal tissues $(\mathrm{X} 2(3)=41.71$, $p<0.001)$, as determined by the Chi-square test.

With respect to cancer grading, there was a significant association between patients' cancer grade and VEGFR-3 $\left(\mathrm{X}^{2}(2)=4.18, p=0.12\right)$, as determined by the KruskalWallis. There was also no significant association between patient's cancer stage and VEGFR-3 $\left(\mathrm{X}^{2}(2)=2.94\right.$,

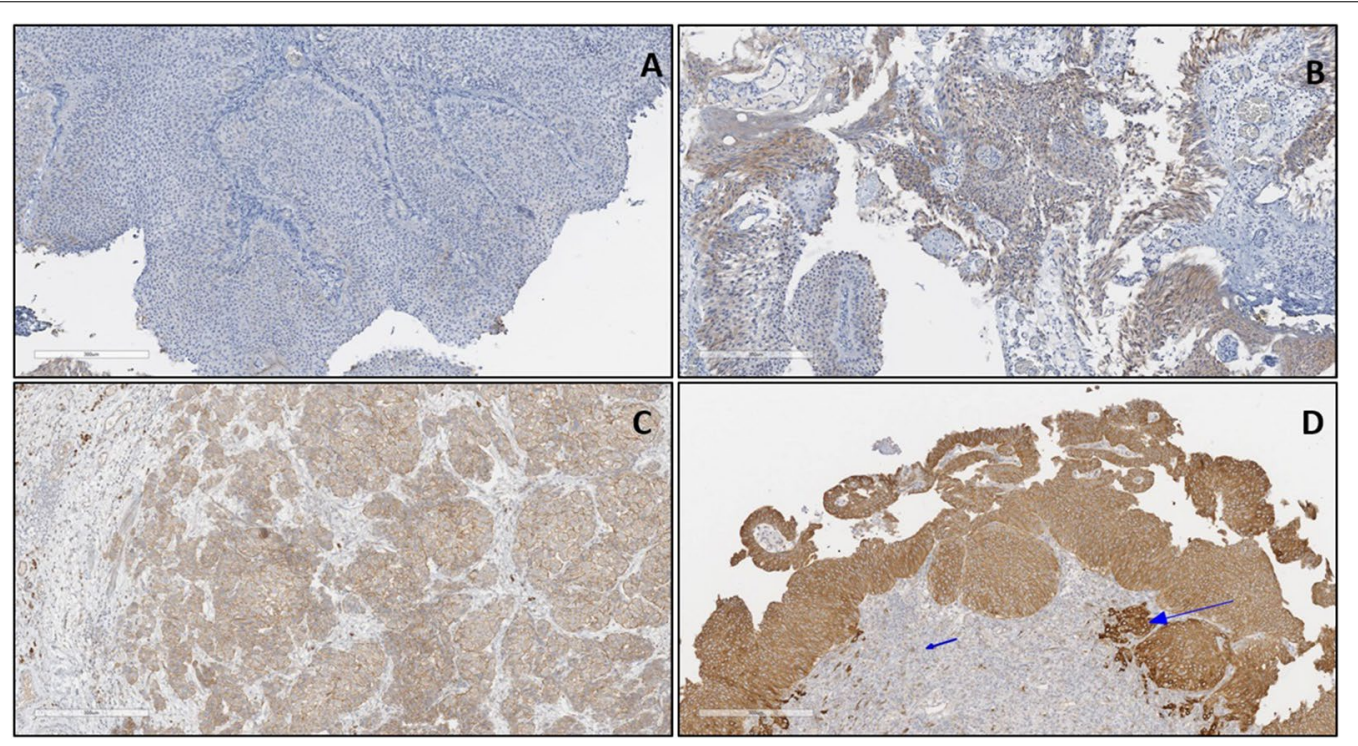

Fig. 5 Anti-COX-2 antibody staining in BC tissues. a Negative: No staining/Positive cytoplasmic/membranous staining in $<5 \%$ of Bladder tumours. $\mathbf{b}$ Positive (+): Weak positive cytoplasmic/membranous staining in up to $20 \%$ of Bladder tumour cells (Brown colour). c Positive (++): Moderate/high positive cytoplasmic/membranous staining (brown colour) in in up to 20-50\% of Bladder tumours. d Positive (+++): Strong positive cytoplasmic/ membranous staining in in up to $>50 \%$ of Bladder tumours (bigger arrow). Note the absence of staining in underlying tissue (smaller arrow). DAB. $\times 40$ magnification 


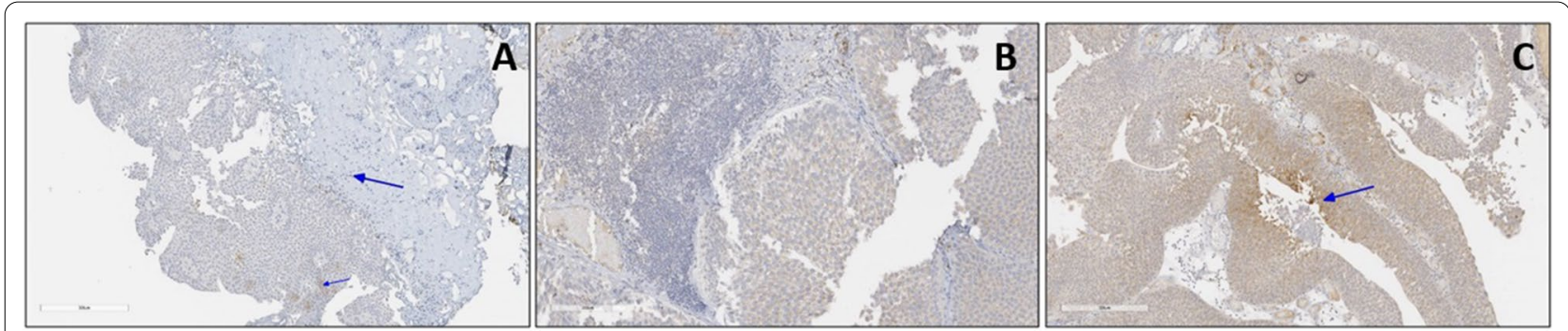

Fig. 6 Anti-CEACAM-1 staining in BC tissues. a Negative: No staining/Positive membranous staining in $<5 \%$ of Bladder tumours. Small blue arrow shows weakly expressed bladder tumours. Big blue arrow shows underlying connective tissue. b Positive (+): Moderate membranous staining in up to $20 \%$ of Bladder tumours. c Positive (++): Positive membranous staining in 20-50\% of Bladder tumour cells (Blue arrows). Ventana ultraview DAB detection. $\times 40$ magnification

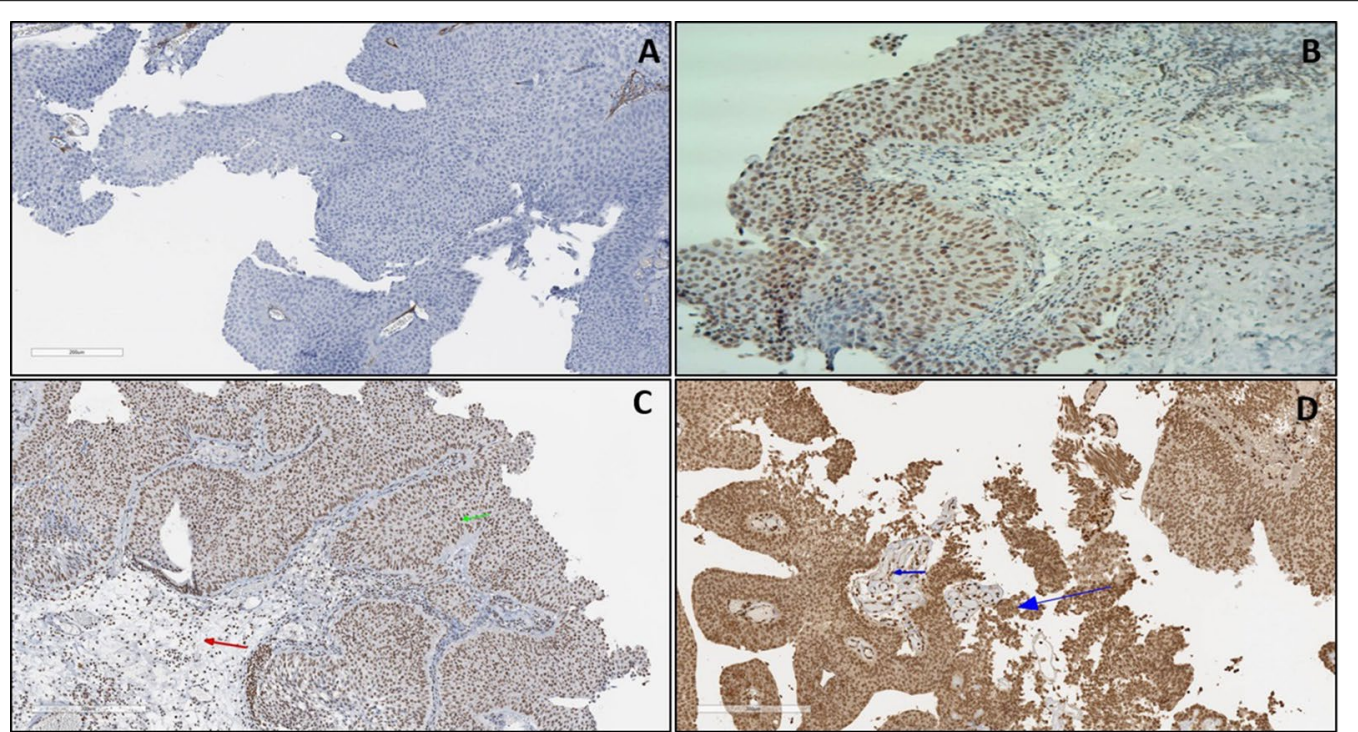

Fig. 7 Anti-VEGFR3 staining in BC tissues. a Negative: No Staining or < 5\% nuclear/cytoplasmic Staining. b Positive (+): Moderate intensity Nuclear/ cytoplasmic staining in up to $25 \%$ of Bladder tumours c Positive (++) Moderate intensity nuclear/cytoplasmic staining in 25-50\% of Bladder tumours (Green arrows). Nonspecific staining in underlying stroma cells (red arrows). d Positive $(+++)$ ): Strong intensity nuclear/cytoplasmic staining in $>50 \%$ of Bladder tumour (big blue arrows). Smaller arrow shows nonspecific staining in stroma cells. Ventana Ultraview DAB. $\times 40$ magnification

$p=0.23)$, as determined by the Kruskal-Wallis test. Table 2 summarises the results for antibody staining in bladder cancer patients.

\section{Discussion}

The main aim of this study was to evaluate the expression of various tissue-based biomarkers in $\mathrm{BC}$ patients and their association with cancer recurrence. This was done by assessing IHC staining in patient tissues following TURBT for the treatment of $\mathrm{BC}$.

The results from this study showed a significant increase in anti-CD31 in vascular endothelial cells located in bladder tumour cells with some staining also located close to the tumour cells. As a marker of angiogenesis, these findings potentially show the presence of increased angiogenesis within the Bladder tumours. The scoring system used in this research examines both staining intensity and percentage positivity in tumour cells and has been used by others [27].

Anti-CD31 patterns reported in this study complements results by others [28] although those author's used a different patient cohort. Both studies however show that, CD31 is a good marker for measuring angiogenesis using IHC. Results from this present study disagree with others [29] as no association between CD31 and cancer grade was observed. This could be 
Table 2 Summarised statistical results for antibody staining in BC

\begin{tabular}{|c|c|c|c|c|}
\hline Antibody & $\begin{array}{l}\text { Overall staining pattern } \\
\text { in patients' Bladder tumours } \\
\text { (Chi square) }\end{array}$ & $\begin{array}{l}\text { Association } \\
\text { between antibody } \\
\text { expression and cancer grade } \\
\text { (Kruskal-Wallis test) }\end{array}$ & $\begin{array}{l}\text { Association } \\
\text { between antibody } \\
\text { expression and cancer stage } \\
\text { (Kruskal-Wallis test) }\end{array}$ & $\begin{array}{l}\text { Association between antibody } \\
\text { expression and cancer } \\
\text { recurrence (Mann-Whitney } \\
\text { test) }\end{array}$ \\
\hline CD31 & $\begin{array}{l}\text { Increased expression in vascu- } \\
\text { lar cells }(p<0.001)\end{array}$ & Not significant $(p=0.257)$ & Significant $(p=0.002)$ & Not significant $(p=0.69)$ \\
\hline Thrombomodulin & $\begin{array}{l}\text { Reduced/loss of expression } \\
\quad(p<0.010)\end{array}$ & Not significant $(p=0.827)$ & Not significant $(p=0.039)$ & Not significant $(p=0.89$ ) \\
\hline HER-2 & $\begin{array}{l}\text { Increased expression } \\
\quad(p<0.032)\end{array}$ & Significant $(p=0.003)$ & Significant $(p<0.001)$ & Not significant $(p=0.91)$ \\
\hline S100P & $\begin{array}{l}\text { Increased expression } \\
\quad(p<0.001)\end{array}$ & Not significant $(p=0.902)$ & Not significant $(p=0.344)$ & Not significant $(p=0.23$ ) \\
\hline CEACAM-1 & $\begin{array}{l}\text { Reduced/loss of expression } \\
\qquad(p<0.001)\end{array}$ & Not significant $(p=0.045)$ & Significant $(p=0.005)$ & Not significant $(p=0.65)$ \\
\hline $\operatorname{cox}-2$ & $\begin{array}{l}\text { Increased expression } \\
\quad(p<0.001)\end{array}$ & Not significant $(p=0.619)$ & Not significant $(p=0.439)$ & Not significant $(p=0.98)$ \\
\hline VEGFR-3 & $\begin{array}{l}\text { Increased expression } \\
\quad(p<0.001)\end{array}$ & Not significant $(p=0.123)$ & Not significant $(p=0.231)$ & Not significant $(p=0.38)$ \\
\hline
\end{tabular}

due to differences in cancer types and grading systems. Patients with cancer stage pTa presented with higher CD31 compared to other BC stages. These findings suggest that increased CD31 in low pTa tumours may have an association with angiogenesis.

In this study, loss of expression or reduced thrombomodulin was observed within bladder tumour cells compared to normal bladder cells. Due to its tumour suppressive properties [30], loss of thrombomodulin observed in this present study, could potentially cause increased tissue differentiation, metastasis and recurrence. Although the exact mechanisms are not fully understood, earlier studies show that, thrombomodulin maintains cell-cell interactions and also inhibits degradation of the ECM; important factors in cancer proliferation [31, 32]. Our findings therefore further complement these earlier studies by highlighting the loss of Thrombomodulin within BC cells. In terms of Bladder specific research however, our research provides new information on Thrombomodulin staining patterns in bladder tumours.

High stage BC was significantly associated with reduced thrombomodulin suggesting that there was reduced cell to cell interaction due to the absence of thrombomodulin. This observation is in agreement with an earlier study which reported that, decreased thrombomodulin was significantly correlated with high cancer stage, differentiation and 5 year survival [33]. In this current study, there was no association between thrombomodulin (at diagnosis) and cancer recurrence. This observation should however be further investigated using larger sample sizes and increasing the length of follow up.
Our results also showed reduced CEACAM-1 in Bladder tumour cells compared to other tissues. Due to its angiogenic properties, an increase in CECAM-1, was expected in BC patients before TURBT. Although increased tissue expression of CEACAM-1 has been reported in human cancers [34], our findings of decreased expression may further explain earlier reports of a dual role of CEACAM-1 in BC [35]. Furthermore, the two IHC reporting systems (traditional scoring system using stain intensity/percentage vrs MVD) produced different results and raises further issues with validation.

Some studies have associated CEACAM-1 with aggressive tumour behaviour (i.e. high grade, advanced stage, metastasis and survival) in different human cancers [36, 37]. In our study, we report a significant association between loss of CEACAM-1 and BC stage and grade. Our study further attempts to evaluate this association with cancer recurrence. In this regard, there was no association between patients' CEACAM-1 (at diagnosis) and $\mathrm{BC}$ recurrence.

There was generally a significant increase in COX-2 in Bladder tumour cells, compared to those in normal tissues. These findings are in agreement with a recent study by others in colonic adenocarcinoma tissues [4]. The results suggest that tumour cells of epithelial origin express high levels of COX-2 probably due to chronic inflammation and may potentially be a good biomarker. Furthermore, high stage and high grade patients presented with high staining intensity and percentage of tumour cells [4]. These observations were also present in the current study and suggests that COX-2 in cancer tissues (especially staining intensity) should be further investigated in BC. 
With regards to cancer stage, our results are in contrast with others [5] who reported significant associations between COX-2 and cancer stage. Although both endometrial carcinoma (EC) and $\mathrm{BC}$ are of epithelial origin, differences in sample size (183 EC vrs $35 \mathrm{BC}$ ), duration of follow up ( 5 yrs. for EC vrs 2 yrs. for BC) and different antibody clones, may explain the differences in results reported by both studies.

The relationship between antibody expression (at diagnosis) vs $\mathrm{BC}$ recurrence was not significant. Nonetheless, the expression patterns of COX-2 in $\mathrm{BC}$, reported in this present study, should be investigated further using larger sample sizes and longer follow up periods. COX-2 seems to be epithelial cancer specific and may be a useful marker for monitoring and management of $B C$ patients following TURBT.

Anti-S100P was investigated in this present study because its cellular expression may interact with growth factors and their receptors, leading to several effects such as tumour proliferation [9]. The results from this present study showed that S100P was significantly expressed in BC cells in comparison with normal Bladder tissue and suggests this protein may be a good marker for identification of BC. In a similar study, S100A8 (which belongs to the same family as S100P) was highly expressed in TCC tissues compared to normal cells [38]. In disagreement with that study however, there was no correlation between S100P expression and patients' cancer grade and stage in this present study.

Although it can be appreciated that S100P will be higher in high grade tumours due to increased cell proliferation [39], that observation was not made in this present study and could potentially be due to low sample size. Furthermore, comparing S100P at diagnosis, with S100P at 2-5 years following treatment, may provide confirmatory information with regards to recurrence and long-term outcome measures.

With regards to recurrence however, findings disagree with other researchers [39] who observed that positive S100P expression was strongly associated with early recurrence in HCC patients. Difference in patient cohorts and sample sizes may explain these variations. The results from this study nonetheless provides new information with regards to S100P staining in bladder tumour cells as well as its association with cancer grade, stage and recurrence following treatment via TURBT.

In various human cancers, different HER-2 rates and patterns have been reported [40-42]. HER-2 expression was therefore investigated in this present study due to its links to cancer growth in various human cancers, especially its utility in breast cancer treatment and management.
Our findings suggest that HER-2 was significantly higher in bladder tumour cells, compared to normal tissues. As a protein involved in signal transduction leading to increased cell proliferation, the increased expression observed in this present study potentially implicates HER-2 in BC growth. These observations complement results by others [43] who reported higher HER-2 expression in colorectal cancer cells compared to normal controls and another group [44] who also reported higher HER-2 in breast cancer patients. The differences between the studies however is that, this present study provides detailed information with regards to antibody clone, scoring system and optimises IHC protocol to the Ventana IHC autostainer.

High grade (G3) patients presented with higher HER-2 expression compared with low grade (G1), in agreement with [45], although their observations were made in breast cancer patients. These findings nonetheless suggest that HER-2 results in higher rate of cell differentiation that potentially leads to increased risk of recurrence and metastasis in $\mathrm{BC}$ patients.

High stage tumours (pT1/pT2) also presented with high HER-2, which complement findings from a previous study [45] involving breast cancer. It can be appreciated that, increasing HER-2 will lead to increased activation of the so-called MAPK pathway, which explains the association with aggressive tumour behaviour.

There was also a significant increase in VEGFR-3 in bladder tumour cells, compared to those in normal tissues. In a previous study [4], VEGF in colonic adenocarcinoma showed intensely positive staining compared to normal control tissues. However, control tissues were moderately positive for VEGF indicating the potential likelihood of false positive reporting. In this present study, there was also non-specific VEGFR-3 staining within nuclei of some underlying muscle cells, lymphatic endothelial cells and basal tissue cells. This observation in this and other study highlights the unspecific nature of VEGF staining, and raises the issues with standardisation in reporting slides.

A limiting factor for this study is the relatively low sample size. Validation of the findings larger multicentre studies could provide clear evidence of a usable biomarker profile as an adjuvant to $\mathrm{BC}$ management.

Future studies may also investigate antibody tissue immunoreaction, serum expression and urine levels simultaneously in all patients. This could provide much clearer data to enhance the search for a usable biomarker profile. 


\section{Conclusion}

It is proposed that by allowing urological surgeons access to laboratory markers such as HER-2, Thrombomodulin, CEACAM-1 and CD31, potentially, in the future, these biomarkers may be used in addition to, or in combination with, currently used scoring systems to predict cancer recurrence and progression.

Ultimately, our research findings may allow current NHS post-operative care protocols to be revised, improved and implemented within $6-8$ years, although larger studies are needed in this area of research in order to make an impact on a national scale, and to promote good practice in the field of urology, pertaining to $\mathrm{BC}$.

\section{Abbreviations \\ BC: Bladder cancer; COX-2: Cyclooxygenase-2; DAB: Diaminobenzidine; FFPE: Formalin-fixed paraffin-embedded; HER-2: Human epidermal growth factor-2; IHC: Immunohistochemistry; MAPK: Mitogen-activated protein kinase; NMIBC: Non-muscle invasive bladder cancer; TCC: Transitional cell carcinoma; TURBT: Transurethral resection of the bladder tumour.}

\section{Acknowledgements}

The authors are grateful to the patients who consented to participate in this study. The authors wish to thank all the staff at the Department of Urology, Wrexham Maelor Hospital and Histopathology department, Glan Clwyd Hospital at Betsi Cadwaladr University Health Board (BCUHB), North Wales, UK, for their support regards our continued research activities.

\section{Authors' contributions}

Conceived concept, study designed and supervision: SFH and IS. Patient recruitment and laboratory experiments: PET, RML and AM. Analysed and interpreted the data: PET and AM. Wrote the paper: PET, SFH and IS. All authors read and approved the final manuscript.

\section{Funding}

The authors thankfully acknowledge the BCUHB Department of Research \& Innovation for their financial support. Funding was provided to cover the costs of essential consumables needed to undertake the study. Funders did not have any role in the study.

\section{Availability of data and materials}

The datasets used and/or analysed during the current study available from the corresponding author on reasonable request.

\section{Ethics approval and consent to participate}

Written ethics committee approval (reference, REC4: 14/WA/0033) was obtained from the Welsh Research Ethics Committee 4 with a Helsinki declaration. The study was undertaken at the BCUHB Wrexham Maelor Hospital and the North Wales Clinical Research Centre, with the study being sponsored by Betsi Cadwaladr University Health Board (BCUHB). Written informed consent for the study was received from all patients.

\section{Consent for publication}

Not Applicable.

\section{Competing interests}

The authors declare that they have no competing interests.

\section{Author details}

${ }^{1}$ North Wales Clinical Research Centre, Betsi Cadwaladr University Health Board (BCUHB), Wrexham Maelor Hospital, Wrexham, Wales, UK. ${ }^{2}$ Faculty of Social and Life Sciences, Wrexham Glyndwr University, Wrexham, UK

${ }^{3}$ Department of Histopathology, Ysbyty Glan Clwd, Betsi Cadwaladr University Health Board (BCUHB), Wrexham, UK. ${ }^{4}$ Department of Biological Sciences,
University of Chester, Chester, UK. ${ }^{5}$ Department of Urology, BCUHB Wrexham Maelor Hospital, Wrexham, Wales, UK.

Received: 19 August 2020 Accepted: 18 November 2020

Published online: 25 November 2020

References

1. Bray F, Ferlay J, Soerjomataram I, Siegel RL, Torre LA, Jemal A. Global cancer statistics 2018: GLOBOCAN estimates of incidence and mortality worldwide for 36 cancers in 185 countries. CA Cancer J Clin. 2018;68(6):394-424.

2. Mariappan P, Zachou A, Grigor KM. Detrusor muscle in the first, apparently complete transurethral resection of bladder tumour specimen is a surrogate marker of resection quality, predicts risk of early recurrence, and is dependent on operator experience. Eur Urol. 2010;57(5):843-9.

3. Yu S-M, Kim S-J. Endoplasmic reticulum stress (ER-stress) by 2-deoxyD-glucose (2DG) reduces cyclooxygenase-2 (COX-2) expression and $\mathrm{N}$-glycosylation and induces a loss of COX-2 activity via a Src kinasedependent pathway in rabbit articular chondrocytes. Exp Mol Med. 2010;42(11):777-86

4. Hedaya M, Helmy A, Ezzat H, Hammam O. Cyclo-oxygenase-2 and vascular endothelial growth factor expression in colorectal cancer patients. Egypt J Surg. 2015;34(1):35-40.

5. Cai S, Zhang Y-x, Han K, Ding Y-q. Expressions and clinical significance of COX-2, VEGF-C, and EFGR in endometrial carcinoma. Arch Gynecol Obstetr. 2017;296(1):93-8.

6. Song J, Ma D, Liu X, Chen Y, Fang J, Lui VWY, et al. Thrombomodulin (TM) in tumor cell differentiation and periphery blood immune microenvironment in oral squamous cell carcinoma. Clin Immunol. 2018;191:27-33.

7. Greineder CF, Johnston $\mathrm{H}$, Villa CH, Gollomp K, Esmon CT, Cines DB, et al. ICAM-1-targeted thrombomodulin mitigates tissue factor-driven inflammatory thrombosis in a human endothelialized microfluidic model. Blood Adv. 2017;1(18):1452-65.

8. Wu C-T, Chang Y-H, Lin P-Y, Chen W-C, Chen M-F. Thrombomodulin expression regulates tumorigenesis in bladder cancer. BMC Cancer. 2014;14(1):375.

9. Jiang H, Hu H, Lin F, Lim YP, Hua Y, Tong $X$, et al. S100P is Overexpressed in squamous cell and adenosquamous carcinoma subtypes of endometrial cancer and promotes cancer cell proliferation and invasion. Cancer Invest. 2016;34(10):477-88.

10. Gibadulinova A, Tothova V, Pastorek J, Pastorekova S. Transcriptional regulation and functional implication of S100P in cancer. Amino Acids. 2011;41(4):885-92.

11. Liu Y, Wang C, Shan X, Wu J, Liu H, Liu H, et al. S100P is associated with proliferation and migration in nasopharyngeal carcinoma. Oncol Lett. 2017;14(1):525-32.

12. Guo L, Chen S, Jiang H, Huang J, Jin W, Yao S. The expression of S100P increases and promotes cellular proliferation by increasing nuclear translocation of beta-catenin in endometrial cancer. Int J Clin Exp Pathol. 2014;7(5):2102-12.

13. Tabrizi MEA, Lancaster TL, Ismail TM, Georgiadou A, Ganguly A, Mistry JJ, et al. S100P enhances the motility and invasion of human trophoblast cell lines. Sci Rep. 2018;8(1):11488.

14. Wang Z, Wang W, Xu S, Wang S, Tu Y, Xiong Y, et al. The role of MAPK signaling pathway in the Her-2-positive meningiomas. Oncol Rep. 2016:36(2):685-95.

15. Siddiqa A, Long LM, Li L, Marciniak RA, Kazhdan I. Expression of HER-2 in MCF-7 breast cancer cells modulates anti-apoptotic proteins Survivin and $\mathrm{BCl}-2$ via the extracellular signal-related kinase (ERK) and phosphoinositide-3 kinase (PI3K) signalling pathways. BMC Cancer. 2008;8:129.

16. Blackwell KL, Burstein HJ, Storniolo AM, Rugo HS, Sledge G, Aktan G, et al. Overall survival benefit with lapatinib in combination with trastuzumab for patients with human epidermal growth factor receptor 2-positive metastatic breast cancer: final results from the EGF104900 study. J Clin Oncol. 2012:30(21):2585-92.

17. Gerhardt H, Golding M, Fruttiger M, Ruhrberg C, Lundkvist A, Abramsson $A$, et al. VEGF guides angiogenic sprouting utilizing endothelial tip cell filopodia. J Cell Biol. 2003;161(6):1163-77. 
18. Eroglu A, Ersoz C, Karasoy D, Sak S. Vascular endothelial growth factor (VEGF)-C, VEGF-D, VEGFR-3 and D2-40 expressions in primary breast cancer: association with lymph node metastasis. Adv Clin Exp Med Off Organ Wroclaw Med Univ. 2017;26(2):245-9.

19. Tammela T, Zarkada G, Wallgard E, Murtomäki A, Suchting S, Wirzenius $M$, et al. Blocking VEGFR-3 suppresses angiogenic sprouting and vascular network formation. Nature. 2008;454(7204):656.

20. Neumaier M, Paululat S, Chan A, Matthaes P, Wagener C. Biliary glycoprotein, a potential human cell adhesion molecule, is down-regulated in colorectal carcinomas. Proc Natl Acad Sci. 1993;90(22):10744-8.

21. Luo W, Tapolsky M, Earley K, Wood CG, Wilson DR, Logothetis CJ, et al. Tumor-suppressive activity of CD66a in prostate cancer. Cancer Gene Ther. 1999;6(4):313.

22. Sha QQ, Wei QZ, Zhu JK, Wang KX, Wang C, Liu HT, et al. Loss of membranous carcinoembryonic antigen-related cell adhesion molecule 1 expression is related to decreased relapse-free survival of hepatocellular carcinoma following liver transplantation. Chin Med J. 2012;125(16):2841-5.

23. O'Brien CD, Lim P, Sun J, Albelda SM. PECAM-1-dependent neutrophil transmigration is independent of monolayer PECAM-1 signaling or localization. Blood. 2003;101(7):2816-25.

24. El Gehani K, Al-Kikhia L, Mansuri N, Syrjanen K, Al-Fituri O, Elzagheid A. Angiogenesis in urinary bladder carcinoma as defined by microvessel density (MVD) after immunohistochemical staining for Factor VIII and CD31. Libyan J Med. 2011;6:24.

25. García-Tello A, Angulo JC, Andrés G, Ramón de Fata F, Sánchez-Chapado M, López JI. Impact of p53, MIB-1 and PECAM-1 expression on the prognosis of urothelial carcinoma of the renal pelvis. Actas Urológicas Españolas (English Ed). 2014;38(8):506-14.

26. Mohamed SY, Mohammed HL, Ibrahim HM, Mohamed EM, Salah M. Role of VEGF, CD105, and CD31 in the prognosis of colorectal cancer cases. J Gastrointest Cancer. 2017;5:1-12.

27. Usuda K, Iwai S, Funasaki A, Sekimura A, Motono N, Ueda Y, et al. Expression and prognostic impact of VEGF, CD31 and alphaSMA in resected primary lung cancers. Anticancer Res. 2018;38(7):4057-63.

28. Qian H, Yang L, Zhao W, Chen H, He S. A comparison of CD 105 and CD31 expression in tumor vessels of hepatocellular carcinoma by tissue microarray and flow cytometry. Exp Ther Med. 2018;16(4):2881-8.

29. Kuang $B H$, Wen $X Z$, Ding $Y$, Peng $R Q$, Cai $P Q$, Zhang $M Q$, et al. The prognostic value of platelet endothelial cell adhesion molecule-1 in non-small-cell lung cancer patients. Med Oncol (Northwood, Lond, Engl). 2013;30(2):536.

30. Tanaka K, Salunya T, Motomiya Y, Motomiya Y, Oyama Y, Yamakuchi M, et al. Decreased Expression of Thrombomodulin in Endothelial Cells by Fibroblast Growth Factor-23/alpha-Klotho. Ther Apheresis Dial. 2017;21(4):395-404

31. Koutsi A, Papapanagiotou A, Papavassiliou AG. Thrombomodulin: from haemostasis to inflammation and tumourigenesis. Int J Biochem Cell Biol. 2008;40(9):1669-73.

32. Weiler H, Lindner V, Kerlin B, Isermann BH, Hendrickson SB, Cooley BC, et al. Characterization of a mouse model for thrombomodulin deficiency. Arterioscler Thromb Vasc Biol. 2001;21(9):1531-7.
33. Hanly A, Redmond M, Winter D, Brophy S, Deasy J, Bouchier-Hayes D, et al. Thrombomodulin expression in colorectal carcinoma is protective and correlates with survival. Br J Cancer. 2006;94(9):1320.

34. Dango S, Sienel W, Schreiber M, Stremmel C, Kirschbaum A, Pantel K, et al. Elevated expression of carcinoembryonic antigen-related cell adhesion molecule 1 (CEACAM-1) is associated with increased angiogenic potential in non-small-cell lung cancer. Lung Cancer. 2008;60(3):426-33.

35. Oliveira-Ferrer L, Tilki D, Ziegeler G, Hauschild J, Loges S, Irmak S, et al. Dual role of carcinoembryonic antigen-related cell adhesion molecule 1 in angiogenesis and invasion of human urinary bladder cancer. Can Res. 2004;64(24):8932-8.

36. Thies A, Moll I, Berger J, Wagener C, Brummer J, Schulze HJ, et al. CEACAM 1 expression in cutaneous malignant melanoma predicts the development of metastatic disease. J Clin Oncol. 2002;20(10):2530-6.

37. Thom I, Schult-Kronefeld O, Burkholder I, Schuch G, Andritzky B, Kastendieck $\mathrm{H}$, et al. Expression of CEACAM-1 in pulmonary adenocarcinomas and their metastases. Anticancer Res. 2009;29(1):249-54.

38. Cui Y-y, Shi A-p, Xu N. Expression of S100A8 protein in human bladder cancer and its clinical significance. Chin J Lab Diagn. 2012;2:017.

39. Yuan RH, Chang KT, Chen YL, Hsu HC, Lee PH, Lai PL, et al. S100P expression is a novel prognostic factor in hepatocellular carcinoma and predicts survival in patients with high tumor stage or early recurrent tumors. PLoS ONE. 2013;8(6):e65501.

40. Hammam O, Nour HH, Mosaad M, AkI M, Khalil H, al Ganzory H, et al. The clinical significance of HER2 protein amplification/expression in urinary bladder lesion. Arab J Urol. 2015;13(2):146-52.

41. Slamon DJ, Leyland-Jones B, Shak S, Fuchs H, Paton V, Bajamonde A, et al. Use of chemotherapy plus a monoclonal antibody against HER2 for metastatic breast cancer that overexpresses HER2. N Engl J Med. 2001;344(11):783-92.

42. Smith I, Procter M, Gelber RD, Guillaume S, Feyereislova A, Dowsett M, et al. 2-year follow-up of trastuzumab after adjuvant chemotherapy in HER2-positive breast cancer: a randomised controlled trial. Lancet. 2007;369(9555):29-36.

43. Hasan R, Bhatt D, Khan S, Khan V, Verma AK, Anees A, et al. Association of Her-2 expression and clinicopathological parameters in colorectal carcinoma in Indian population. Open Access Macedonian J Med Sci. 2018;7(1):6-11.

44. Du JW, Xu KY, Fang LY, Qi XL. Clinical significance of Mena and Her-2 expression in breast cancer. Eur J Gynaecol Oncol. 2012;33(5):455-8.

45. Jana D, Mandal S, Mukhopadhyay M, Mitra D, Mukhopadhyay SK, Sarkar DK. Prognostic significance of HER-2/neu and survival of breast cancer patients attending a specialized breast clinic in Kolkata, Eastern India. Asian Pacific J Cancer Prev APJCP. 2012;13(8):3851-5.

\section{Publisher's Note}

Springer Nature remains neutral with regard to jurisdictional claims in published maps and institutional affiliations.

Ready to submit your research? Choose BMC and benefit from:

- fast, convenient online submission

- thorough peer review by experienced researchers in your field

- rapid publication on acceptance

- support for research data, including large and complex data types

- gold Open Access which fosters wider collaboration and increased citations

- maximum visibility for your research: over $100 \mathrm{M}$ website views per year

At $\mathrm{BMC}$, research is always in progress.

Learn more biomedcentral.com/submissions 